\section{Antibiotics: support US policy change}

As a microbiologist and member of the US Congress, I applaud your call to action on the overuse of antibiotics in agriculture (Nature 499, 379, 394-396, 398-400; 2013). I have been fighting since 1999 to pass the Preservation of Antibiotics for Medical Treatment Act (PAMTA), which would ban the use of eight classes of medically important antibiotics in agriculture, with exceptions for treating sick animals.

In the United States, antibiotics are often distributed at subtherapeutic doses to healthy farm animals to compensate for crowded and unsanitary living conditions or to promote growth.

In June, science ministers from the G8 nations discussed antibiotic resistance and committed to clamping down on overuse of antibiotics in health care, farming and fisheries. It is only through such coordinated international action that we can begin to hold back the tide of antibiotic-resistant bacteria.

Policy-makers need help, as you point out. I urge US readers to take a stand on this issue and ask their representatives and senators to co-sponsor PAMTA in the House of Representatives or the Preventing Antibiotic Resistance Act in the Senate (see www.louise.house.gov).

Louise M. Slaughter Washington DC, USA.

eric.walker@mail.house.gov

\section{Antibiotics: collect more US data}

The paucity of data on antibiotic use in livestock and poultry in the United States makes it hard for scientists to assess the relationship with antibiotic resistance (Nature 499, 398-400; 2013). More comprehensive data need to be collected and made freely available to bring the United States in line with countries such as Denmark, where antibiotic use can be traced to individual animals.

The only US antibiotic data available are the sales figures that drug companies report to the Food and Drug Administration (FDA), which are published as total sales for each antibiotic class. Such broad aggregated data are of limited value, beyond confirming the extensive use of antibiotics in animals reared for food.

In February 2011, the Center for a Livable Future at the Johns Hopkins University in Baltimore, Maryland, and the Government Accountability Project (GAP) in Washington DC attempted to obtain more detailed antibiotics data from the FDA under the Freedom of Information Act. The FDA denied the request, claiming that these commercial data are confidential. In December 2012, GAP sued the FDA for access to the data (the case is ongoing).

Given that the misuse of antibiotics erodes their efficacy, there is an urgent need for greater transparency over their use. We contend that the FDA, as a public-health agency, is responsible to the public, not to the industry it regulates. It is imperative that more antibiotic data be released so that evidencebased public-health policies can be developed to combat antibiotic resistance.

Robert S. Lawrence, Keeve E. Nachman, Tyler J. Smith Johns Hopkins Center for a Livable Future, Baltimore, Maryland, USA.

tylsmith@jhsph.edu

\section{Fukushima: unpaid soil-research effort}

We and other particle physicists working voluntarily in Fukushima, Japan, where people were evacuated in 2011 because of the nuclear accident, are neither "opportunistic" nor "adventurous", as you quote (see Nature 499, 265-266; 2013). We seek only to use our expertise to find a way to reduce the radioactive contamination of the area's soil.

We give up our weekends to work independently on analysing soil samples — a gruelling task in the winter months. We give lectures on radiation to those forced to leave their homes, so that they can better understand their plight and our efforts to remedy it. Our goal is to enable local farmers' livelihoods eventually to be restored.

Tokio Kenneth Ohska, Hiroshi Iwase High Energy Accelerator Research Organization, Tsukuba, Japan.

hiroshi.iwase@kek.jp

\section{Fukushima: 'ecolab' branding insensitive}

As the organizers of a

symposium on the genetic effects of radiation following the Fukushima disaster - held at this year's annual meeting of the Society for Molecular Biology and Evolution - we object strongly to the headline of your report 'Fukushima offers real-time ecolab' (Nature 499, 265-266; 2013).

In our view and those of many others from Japan and elsewhere who have communicated their objections to us, it conveys a lack of empathy among researchers for the suffering of the people and animals affected by the Fukushima power-plant disaster.

Scientists working on the consequences of the catastrophic events of March 2011, including the symposium panellists and ourselves, always take into primary consideration the pain of people in Fukushima. The researchers would never insult them by branding them or their natural environment as experimental material.

Your headline does not reflect the aims of our symposium or of the panellists' research

Tomoko Y. Steen Georgetown University, Washington DC, USA. tys8@georgetown.edu

Marta L. Wayne University of

Florida, Gainesville, USA.

\section{Curb indigenous fears of REDD+}

One of Panama’s leading traditional indigenous authorities, the Guna General Congress, in June banned a project aimed at reducing emissions from deforestation and forest degradation (REDD+). The Congress, which controls about $7 \%$ of Panama's primary forests, went further, forbidding organizations in the Guna Yala territory from engaging in REDD+ activities, and walked out of REDD+ discussions. We believe that this crisis stems from a failure to build REDD+ capacity for indigenous people at all levels: it is time to pay more than lip service to their full and effective participation in REDD+.

REDD+ started well in Panama. The country put the rights of indigenous peoples on the agenda of the United Nations Framework Convention on Climate Change, and REDD+ project promoters complied with consent procedures of the Guna General Congress. Panama's National Coordinating Body of Indigenous Peoples (COONAPIP) drafted a plan in 2011 for comprehensive REDD+ capacity-building efforts in each indigenous territory. This would have stimulated debates about fears that REDD+ might threaten traditional land uses and rights, as well as possible ways forward. Knowledge transfer is the best antidote for the fear of REDD+.

The plan failed to receive UN funding. COONAPIP withdrew from the UN-REDD programme in February and called on indigenous peoples globally to proceed cautiously on REDD-related matters. If this fear of participation spreads beyond Guna Yala, the programme could be jeopardized in other Latin American countries.

Catherine Potvin, Javier Mateo-Vega McGill University, Montreal, Canada; and Smithsonian Tropical Research Institute, Panama. catherine.potvin@mcgill.ca 